\title{
Transcriptome analysis of osteosarcoma identifies suppression of wnt pathway and up-regulation of adiponectin as potential biomarker
}

\author{
Aare Märtson ${ }^{1,2}$, Sulev Kõks ${ }^{3 *}$, Ene Reimann ${ }^{3}$, Ele Prans ${ }^{3}$, Triin Erm ${ }^{4}$ and Katre Maasalu ${ }^{1,2}$ \\ *Correspondence: Sulev.Koks@ut.ee \\ 'Department of Traumatology and Orthopedics, University of Tartu, Estonia. \\ ${ }^{2}$ Traumatology and Orthopaedics Clinic, Tartu University Hospital, Tartu, Estonia. \\ ${ }^{3}$ Department of Pathophysiology, University of Tartu, Estonia. \\ ${ }^{4}$ Department of Pathology, Tartu University Hospital, Tartu, Estonia.
}

\begin{abstract}
Osteosarcoma (OS) is primary malignant bone tumour with complicated early diagnosis. There are no specific markers currently available for predicting the prognosis and chemosensitivity of OS. In present study we performed transcriptome profiling of single patient tumour tissue with RNA-seq technology. We analysed surgically removed sarcoma sample from single 16 years old male patient. Transciptome analysis was done with RNA-seq technology, bioinformatics with Lifescope and R Bioconductor. Validation experiments were done with quantitative real-time PCR (QRTPCR). After quality and coverage filtering, RNA-seq experiment resulted 29,311,899 mapped reads for sarcoma and 22,099,159 mapped reads for normal bone tissue. 65 genes were differentially expressed with FDR corrected statistical significance below 0.05. Seven genes were down-regulated and 58 genes were up-regulated in sarcoma. The most highly up-regulated gene in sarcoma was adiponectin, ADIPOQ (with adjusted p-value 5.5E-07, log2 fold change was 7.9). Many of the genes we found are related to the adipose tissue metabolism (ADIPOQ, PLIN1, FABP4) and to the Wnt signalling suppression (WIF1, SOST). We also found novel fusion transcript between the genes LMTK2 and ZSWIM5. LMTK2 is lemur tyrosine kinase 2, and it has been shown to be involved in NGF-TrkA signalling. Interestingly, studies support the involvement of LMTK2 in development of prostate cancer. ZSWIM5 is zinc finger SWIM domain protein 5 and its function is not known. Immunohistochemical analysis confirmed positive staining for adiponectin in osteosarcoma. This paper is a good illustration how transcriptome analysis can find new biomarkers and targets for complex diseases.
\end{abstract}

Keywords: Osteosarcoma, transcriptome, adiponectin, WIF1

\section{Introduction}

Osteosarcoma (OS) is the most frequent primary bone tumour in children and adolescents [1]. It is malignant mesenchymal sarcoma and if left untreated it progresses to local and systemic disease. OS is devastating disease with poor early diagnosis and a low long-term survival rate despite significant improvements in therapy. Although OS is rare disease, its high mortality makes its overall contribution to cancer mortality high [2]. Occasionally familial involvement in OS has been observed. Therefore, genetic susceptibility plays some role in the disease development and genetic regulation seems to be important in disease progression. P53 has frequently found to be involved in OS development and it is suggested as a target for gene therapy of sarcoma $[3,4]$. Wnt signalling pathway is involved in the bone formation and also in sarcoma development [5-7]. According to current understanding activation of Wnt pathway leads to the development of OS [8]. On the other hand, in another recent study the inactivation of Wnt signalling in high-grade OS biopsies was shown [9]. Activation of Wnt signalling was shown to inhibit proliferation of cells and promote osteogenic differentiation in osteosarcoma cell lines [9]. Therefore, the results on the Wnt signalling involvement in OS development are somewhat controversial. Most likely, this is caused by the differences in models and methods applied in different studies.

In many cases, new fusion transcripts in malignant samples have been described and this reflects genomic complexity of the OS [10]. OS is genomically unstable tumour what makes its chemical and biological therapy complicated [11]. This cancer is very aggressive and develops distant metastases in $45 \%$ even with the intensive neoadjuvant treatment with multiple chemotherapeutic drugs [12]. Survival of patients has increased only slightly and no other significant improvement has been made since decades [13-15]. Therefore, new drugs are seriously needed for OS. Better understanding of the OS biology and genomics can give us new information and potential targets for drug development.

In present study we performed transcriptome profiling of single patient tumour tissue with RNA-seq technology. We compared tumorous tissue with patient's own normal bone tissue in order to find specific profile in transcriptome characteristic for the sarcoma. RNA-seq is most comprehensive analytical tool for transcriptome profiling and in addition to conventional gene expression profiling it allows finding of transcriptional aberrations, fusions, what can be potentially 
Märtson et al. Genomics Discovery 2013,

important for the tumorigenesis. Although this study is exploratory and its results need to be confirmed by further studies, we were able to describe the genetic network behind OS and new potential biomarker.

\section{Methods \\ Subject}

Patient, 16 years old male, became ill with complaints of pain in left knee area. History of trauma was missing and GP administered painkillers and vitamins. After 6 months he returned to GP with complaints of pain, swelling and dysfunction in left distal femur and knee area. The swelling line observed in left femoral distal region, the area was thicker and painful during the touch. No changes in skin color were detected. The X-ray investigation showed additional shading and structural change in distal part of left femur. For detailed investigation the MRI was performed and as a result malignant process was suspected. Patient was hospitalized and bone biopsy was taken for histological investigation. The diagnosis of osteosarcoma was confirmed.

Chemotherapy for osteosarcoma started by SSG XIV treatment protocol. After 3 month of chemotherapy surgical removal of tumor (distal part of femoral bone with knee joint) and replacement of knee and lower part of femur with megaprosthesis was performed. Materials for this study were collected from surgically removed tissue.

\section{RNA extraction and RNA-seq}

RNA was extracted by using the Trizol combined with columns (RNeasy Mini kit, Qiagen Sciences, Maryland, USA). Up to $100 \mathrm{mg}$ of tissue was used for extractions. In brief, mortar was washed with DEPC water (about $20 \mathrm{~min}$ ) and bone sample was placed into mortar. Liquid nitrogen was added three times. Each time the nitrogen was allowed to boil off and finally, bone was grinded into a powder. Trizol was added to the homogenized bone tissue and the mix was transferred into a polypropylene tube, followed by centrifugation. Supernatant was transferred into a new tube and RNA extraction with RNeasy Mini kit was followed.

The quality of total RNA was evaluated with Agilent 2100 Bioanalyzer and RNA 6000 Nano kit (Agilent Technologies Inc., California, USA). The average RIN number for the samples was at least $7.50 \mathrm{ng}$ of total RNA was amplified by applying Ovation RNA-Seq System V2 (NuGen, Emeryville, CA, USA) after which the resulting CDNAs were pooled in equal amount and the pool was used to prepare the DNA fragment library with SOLiD System chemistry (Life Technologies Corp., Carlsbad, CA, USA). Sequencing was performed using SOLiD 5500xl platform and paired-end DNA sequencing chemistry (Life Technologies Corp., Carlsbad, CA, USA). 75 bp from forward and 35 bp from reverse direction was sequenced and altogether at least 40 million reads per sample was received, which is sufficient for the evaluation of expression pattern of the transcriptome.

\section{Bioinformatics analysis}

For bioinformatics analysis Lifescope software was used. This is proprietary software developed by Life Technologies and allows complete analysis of sequencing data from mapping to the annotation and structural analysis. Briefly, raw data were mapped to reference genome and list of gene counts was generated. In addition, exon junctions and gene fusions were detected to find alternative transcriptional modifications.

For statistical analysis DeSeq package for $\mathrm{R}$ was used [16] DeSeq is a package what is specifically developed for RNA-seq or other counts data. The package DeSeq provides methods to test for differential expression by use the negative binomial distribution and a shrinkage estimator for the distribution's variance [16]. DeSeq also allows performing analysis of the data without replicates. In such case, the dispersion is estimated from comparing their counts across conditions as replacement for a proper estimate of the variance across the replicates. Package performs sample comparison and also adjusts P-value to overcome multiple testing problem. DeSeq package uses Benjamini-Hochberg procedure, which controls for false discovery rate (FDR) [17].

Ingenuity pathway analysis (IPA, Ingenuity Systems, http:// www.ingenuity.com) software was used to functionally annotate RNA-seq results.

\section{Quantitative real-time PCR}

For gene-expression analysis first strand CDNA was synthesized by using random primers and SuperScript ${ }^{\mathrm{TM}}$ III Reverse Transcriptase (Invitrogen, USA). Gene expression levels of the selected 11 genes were analyzed by applying TaqMan Assay-On-Demand (FAM-labeled MGB-probe) gene expression assay mix (20x, Applied Biosystems, Foster City, CA, USA) and TaqMan Universal PCR Master Mix (Applied Biosystems, Foster City, CA, USA). For quantitative real-time PCR (qRT-PCR) analysis the ABI PRISM 7900HT Fast Real-Time PCR System equipment (PE Applied Biosystems, USA) and the ABI PRISM 7900 SDS 2.2.2 Software were used. Every reaction was made in four replicates to minimize possible errors. All reactions were performed in a final volume of $10 \mu \mathrm{l}$, using 50-100 ng of CDNA. Data is presented as $2^{-\Delta C T}$ calculated in relation to the HPRT1. For HPRT1 analysis, primer for exon 6 (5'-GACTTTGCTTTCCTTGGTCAGG-3') and primer for exon 7 (5'-AGTCTGGCTTATATCCAACACTTCG- $3^{\prime}$ ) and VIC-labeled MGB probe was used. All the assays and respective genes used in RT-PCR are listed in (Table 1).

\section{Immunohistochemical staining}

We used Anti-Adiponectin antibody ab22554 [19F1] from ABCAM and Ventana BenchMark ULTRA slide-staining system. Slides were baked $\left(62^{\circ} \mathrm{C}, 12\right.$ minutes) and deparaffinized $\left(65^{\circ} \mathrm{C}\right)$, antigen was retrieved with the ULTRA CC1 $64 \mathrm{~min}\left(95^{\circ} \mathrm{C}\right)$ and then blocked with UV inhibitor ( $3 \% \mathrm{H}_{2} \mathrm{O}_{2}, 4$ minutes). Slides were incubated with primary antibody (dilution 1:100) for 32 minutes $\left(37^{\circ} \mathrm{C}\right)$ and staining was detected with UltraView 
Märtson et al. Genomics Discovery 2013,

Table 1. The list of Taqman real-time PCR assays and the genes analysed to confirm RNA-seq data.

\begin{tabular}{ll}
\hline Gene & \multicolumn{1}{c}{ TaqMan Assay } \\
\hline ADIPOQ & Hs00605917_m1 \\
WIF1 & Hs00183662_m1 \\
TRDN & Hs00952568_m1 \\
PLIN1 & Hs00160173_m1 \\
CHI3L1 & Hs00609691_m1 \\
CHI3L2 & Hs00970220_m1 \\
ADH1B & Hs00605175_m1 \\
PANX3 & Hs00364808_m1 \\
SOST & Hs00228830_m1 \\
IGLL5 & Hs00382306_m1 \\
LOC255167 & Hs03680799_m1 \\
\hline
\end{tabular}

Universal DAB Detection Kit.

\section{Results \\ Identification of differentially expressed genes between normal bone and osteosarcoma}

After quality and coverage filtering, RNA-seq experiment yielded 29,311,899 mapped reads for sarcoma sample and $22,099,159$ mapped reads for normal bone tissue. We had annotated 24,922 genes and 21,825 genes were expressed in one or another sample. Statistical analysis with DeSeq identified that 65 genes were differentially expressed with multiple testing corrected statistical significance below 0.05 (Table 2). 7 genes were up-regulated in normal tissue and 58 genes were up-regulated in sarcoma. The most highly upregulated gene by statistical significance was adiponectin, ADIPOQ (with adjusted $p$-value $5.5 \mathrm{E}^{-07}$ ). Adiponectin was almost the most activated gene by fold change, log 2 fold change was 7.9 , what is about 250 times over-expressed compared to control tissue. By fold change the most up-regulated gene was triadin, TRDN. TRDN has log2 fold change 8.2 (Table 2).

We made two observations by looking the list of the differentially expressed genes. First, very few genes were overexpressed in the healthy bone compared with sarcoma. This means, sarcoma produces very actively (in high levels) large number of genes. And second, many of the genes we found are related to the adipose tissue metabolism (adiponectin, perilipin 1, fatty acid binding protein 4 ). We also found typical genes for bone tissue (e.g. Wnt inhibitory factor 1, WIF1 and sclerostin, SOST), but quite many of the genes are characteristic for adipose tissue. There are also genes participating in immune response. WIF1 is a gene what is involved in different malignancies and it regulates cell cycle $[18,19]$. In recent study its involvement in osteosarcoma was shown [20].

In addition to the counts data, RNAseq enables detection of potential fusion transcripts. In sarcoma sample, we found novel fusion transcript between the genes LMTK2 and
ZSWIM5 (Table 3, Figure 1). LMTK2 is lemur tyrosine kinase 2, and it has been shown to be involved in NGF-TrkA signalling [21]. Interestingly, several studies support the involvement of LMTK2 in development of prostate cancer [22-24]. ZSWIM5 is zinc finger SWIM domain protein 5 and its function is not known very well.

\section{Confirmation of differentially expressed gene with quantitative RT-PCR}

We tested 11 genes with most significant differences from RNAseq data. Quantitative real-time PCR confirmed differences with almost all tested 11 genes (Figure 2). Thus, in case of PANX3 we found significant down-regulation in sarcoma samples and all other genes were up-regulated in sarcoma. Only in case of TRDN we didn't find difference between normal bone and sarcoma sample. This is peculiar, as the difference based in RNAseq analysis was very large. As RNAseq gives information also based on exons, we checked the situation with TRDN. Indeed, we found that in sarcoma sample for exon 1 in TRDN genes there were 361 reads (RPKM 16.96). There were reads also matching to other exons (RPKMs around 3...10). In normal bone sample, no reads were mapped to any exons of TRDN gene. As the real-time PCR assay for TRDN (Hs00952568_m1) detects only junction between 2 and 3 exons, this may explain the discrepancy between RNAseq and RT-PCR data. Therefore, in case of TRDN we have alterative splicing between test samples and this generates some confusion. TRDN is known to have several different transcripts and different alternative forms exist [25]. However, as the function of TRDN is not known, this finding should be taken cautiously.

All genes with statistically significant gene expression levels were used for clustered analysis. This analysis revealed clear differences in gene expression profiles in analysed two samples (sarcoma and normal bone, heatmap in (Figure 3). This indicates correct sample preparation and grouping.

\section{Functional annotation of the RNA-seq data}

Functional annotation of RNAseq data was performed with the IPA system. We filtered data and for log2FC values cutoff 4 was used. Most significantly enriched network was network called "Hematological Disease, Metabolic Disease, Endocrine System Development and Function" (Figure 4). This means that the genes with the largest differences are related to the oncogenesis and endocrine regulation.

\section{Confirmation of adiponectin expression with immuno- histochemistry}

We analysed histological sample of osteosarcoma with adiponectin antibody and found strong staining in the osteoid, matrix and endothelial cells (Figure 5). Therefore, adiponectin expression in osteosarcoma was also confirmed in protein level.

\section{Discussion}

Main finding of our study is that compared to normal bone 
Märtson et al. Genomics Discovery 2013,

http://www.hoajonline.com/journals/pdf/2052-7993-1-3.pdf

doi: $10.7243 / 2052-7993-1-3$

Table 2. Differentially expressed genes between normal bone and osteosarcoma. Genes are ranked based on the adjusted p-values.

\begin{tabular}{|c|c|c|c|c|c|c|c|}
\hline Gene ID & Normal & Sarcoma & FC & $\log 2 \mathrm{FC}$ & pval & padj & Gene name \\
\hline ADIPOQ & 7.64 & 1819.74 & 238.27 & 7.9 & $2.77 \mathrm{E}-11$ & $5.59 \mathrm{E}-07$ & adiponectin \\
\hline WIF1 & 15.27 & 2099.10 & 137.42 & 7.1 & $2.57 \mathrm{E}-10$ & $2.59 \mathrm{E}-06$ & WNT inhibitory factor 1 \\
\hline TRDN & 1.09 & 330.39 & 302.82 & 8.24 & $1.39 \mathrm{E}-08$ & $9.31 \mathrm{E}-05$ & triadin \\
\hline LOC255167 & 6.55 & 527.59 & 80.59 & 6.33 & $5.69 \mathrm{E}-08$ & 0.0003 & -- \\
\hline PLIN1 & 5.46 & 443.69 & 81.33 & 6.35 & $9.23 \mathrm{E}-08$ & 0.0004 & perilipin 1 \\
\hline CHI3L1 & 9.82 & 595.91 & 60.69 & 5.92 & $1.26 \mathrm{E}-07$ & 0.0004 & chitinase 3-like 1 (cartilage glycoprotein-39) \\
\hline ADH1B & 1.09 & 227.47 & 208.48 & 7.7 & $1.63 \mathrm{E}-07$ & 0.0005 & alcohol dehydrogenase 1B (class I). beta polypeptide \\
\hline PANX3 & 6651.11 & 221.41 & 0.03 & -4.91 & $5.44 \mathrm{E}-07$ & 0.0003 & pannexin 3 \\
\hline SOST & 168.02 & 5307.86 & 31.59 & 4.98 & $4.5 \mathrm{E}-07$ & 0.0001 & sclerostin \\
\hline CHI3L2 & 36.01 & 1254.1 & 34.83 & 5.12 & $5.46 \mathrm{E}-07$ & 0.0001 & chitinase 3-like 2 \\
\hline IGLL5 & 7.64 & 420.34 & 55.04 & 5.78 & $4.52 \mathrm{E}-07$ & 0.0001 & immunoglobulin lambda-like polypeptide 5 \\
\hline IFI27 & 98.2 & 2797.07 & 28.48 & 4.83 & $9.88 \mathrm{E}-07$ & 0.0017 & interferon. alpha-inducible protein 27 \\
\hline FABP4 & 20.73 & 691.05 & 33.34 & 5.06 & $1.38 \mathrm{E}-06$ & 0.0021 & fatty acid binding protein 4 . adipocyte \\
\hline MMP3 & 0.0 & 130.60 & Inf & Inf & $1.49 \mathrm{E}-06$ & 0.0021 & matrix metallopeptidase 3 \\
\hline DNASE1L3 & 4.36 & 252.55 & 57.87 & 5.85 & $1.84 \mathrm{E}-06$ & 0.0025 & deoxyribonuclease I-like 3 \\
\hline GZMA & 0.0 & 122.82 & Inf & Inf & $1.98 \mathrm{E}-06$ & 0.0025 & granzyme A (granzyme 1) \\
\hline IGJ & 13.09 & 452.34 & 34.55 & 5.11 & $2.49 \mathrm{E}-06$ & 0.0029 & immunoglobulin J polypeptide \\
\hline CHRDL1 & 16.37 & 505.96 & 30.92 & 4.95 & $2.9 \mathrm{E}-06$ & 0.0033 & chordin-like 1 \\
\hline WDR72 & 21.82 & 630.51 & 28.89 & 4.85 & $3.11 \mathrm{E}-06$ & 0.0033 & WD repeat domain 72 \\
\hline PTX3 & 75.28 & 1628.6 & 21.63 & 4.44 & $5.75 \mathrm{E}-06$ & 0.0058 & pentraxin 3 , long \\
\hline RGS18 & 2.18 & 151.36 & 69.36 & 6.12 & 7.97E-06 & 0.0074 & regulator of G-protein signaling 18 \\
\hline GFRA1 & 14.18 & 394.39 & 27.81 & 4.8 & $8.12 \mathrm{E}-06$ & 0.0074 & GDNF family receptor alpha 1 \\
\hline PRG4 & 952.5 & 17119.72 & 17.97 & 4.17 & $1.02 \mathrm{E}-05$ & 0.0086 & proteoglycan 4 \\
\hline C7 & 3.27 & 171.25 & 52.32 & 5.71 & $1.02 \mathrm{E}-05$ & 0.0086 & complement component 7 \\
\hline RSAD2 & 55.64 & 1086.31 & 19.52 & 4.29 & $1.25 \mathrm{E}-05$ & 0.0097 & radical S-adenosyl methionine domain containing 2 \\
\hline EPYC & 14.18 & 368.45 & 25.98 & 4.7 & $1.24 \mathrm{E}-05$ & 0.0097 & epiphycan \\
\hline HBB & 53.46 & 1030.09 & 19.27 & 4.27 & $1.35 \mathrm{E}-05$ & 0.0101 & hemoglobin, beta \\
\hline F13A1 & 180.03 & 2990.80 & 16.61 & 4.05 & $1.94 \mathrm{E}-05$ & 0.0132 & coagulation factor XIII. A1 polypeptide \\
\hline CRTAC1 & 126.56 & 2144.07 & 16.94 & 4.08 & $1.92 \mathrm{E}-05$ & 0.0132 & cartilage acidic protein 1 \\
\hline
\end{tabular}

Table 3. Description of the fusion transcript we found in osteosarcoma sample during RNAseq analysis.

\begin{tabular}{llllllllll}
\hline E1 & E1-reference & E2 & E2-reference & E1-size & E2-size & E1-readcount & E2-readcount & E1-RPKM & E2-RPKM \\
\hline LMTK2-11 & Chr7 & ZSWIM5-2 & Chr1 & 2959 & 357 & 157 & 8 & 5.99 & 2.53 \\
\hline
\end{tabular}

tissue, osteosarcoma expresses quite many specific transcripts. These transcripts can be taken as potential biomarkers or new drug targets for the osteosarcoma. The genes found in our study, seem to have involvement in development of OS or in other cancers. However, more information about their roles in OS development is needed. As this study is also exploratory additional studies should be performed in order to test their validity. We try to analyse the list of genes in the light of more recent findings.
Adiponectin (ADIPOQ) seems to be good biomarker for osteosarcoma studies. While ADIPOQ has not been related to OS in earlier studies, there are some studies where the role of ADIPOQ in cancer development has been addressed. Namely, one very recent meta-study revealed the association of ADIPOQ with risk of cancer development [26]. In addition, adiponectin is able to induce motility of prostate cancer and chondrosarcoma cells $[\mathbf{2 7}, \mathbf{2 8}]$. Moreover, adiponectin is closely associated with bone remodelling and bone 
Märtson et al. Genomics Discovery 2013,

http://www.hoajonline.com/journals/pdf/2052-7993-1-3.pdf

doi: $10.7243 / 2052-7993-1-3$
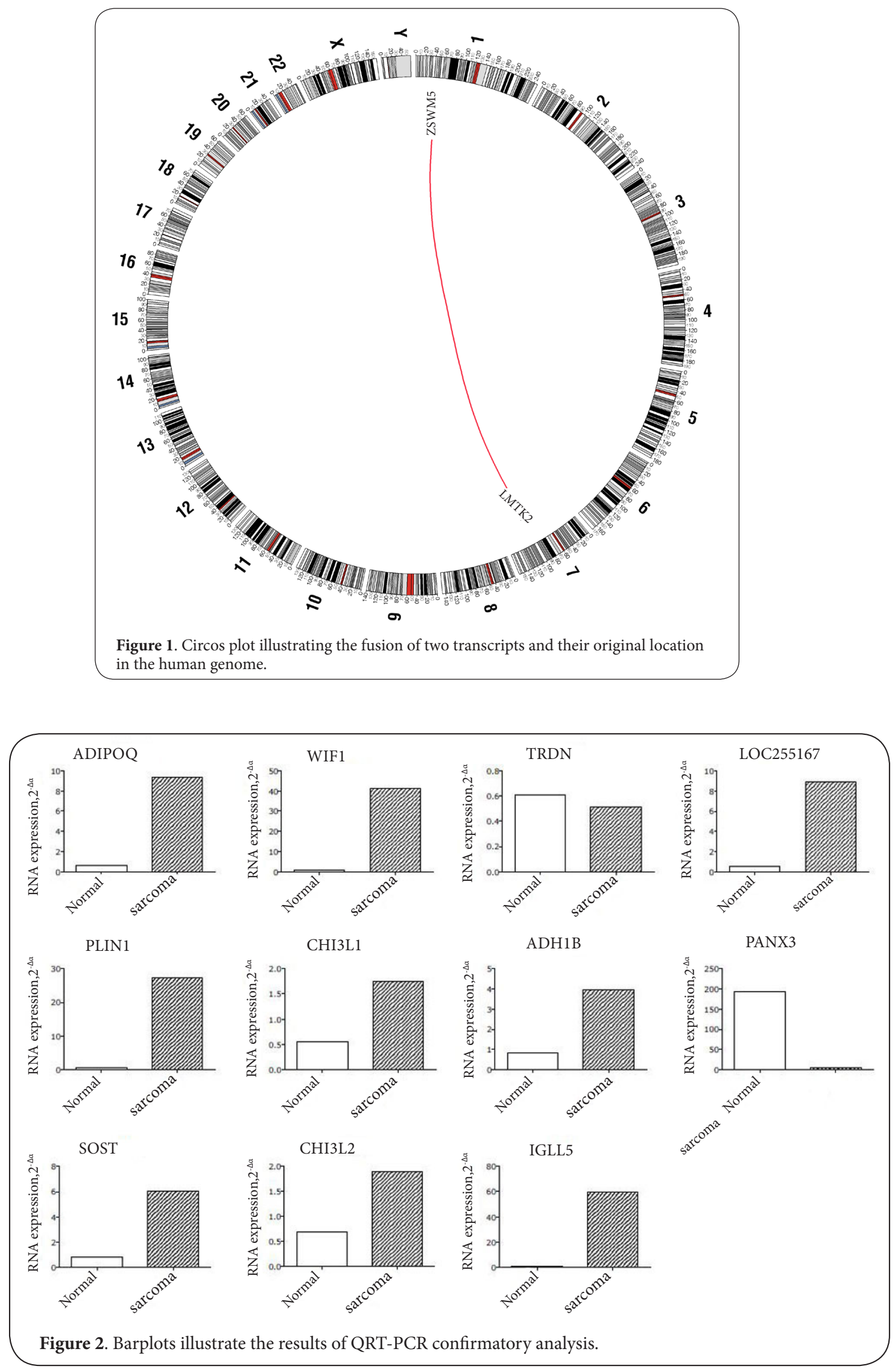

5 


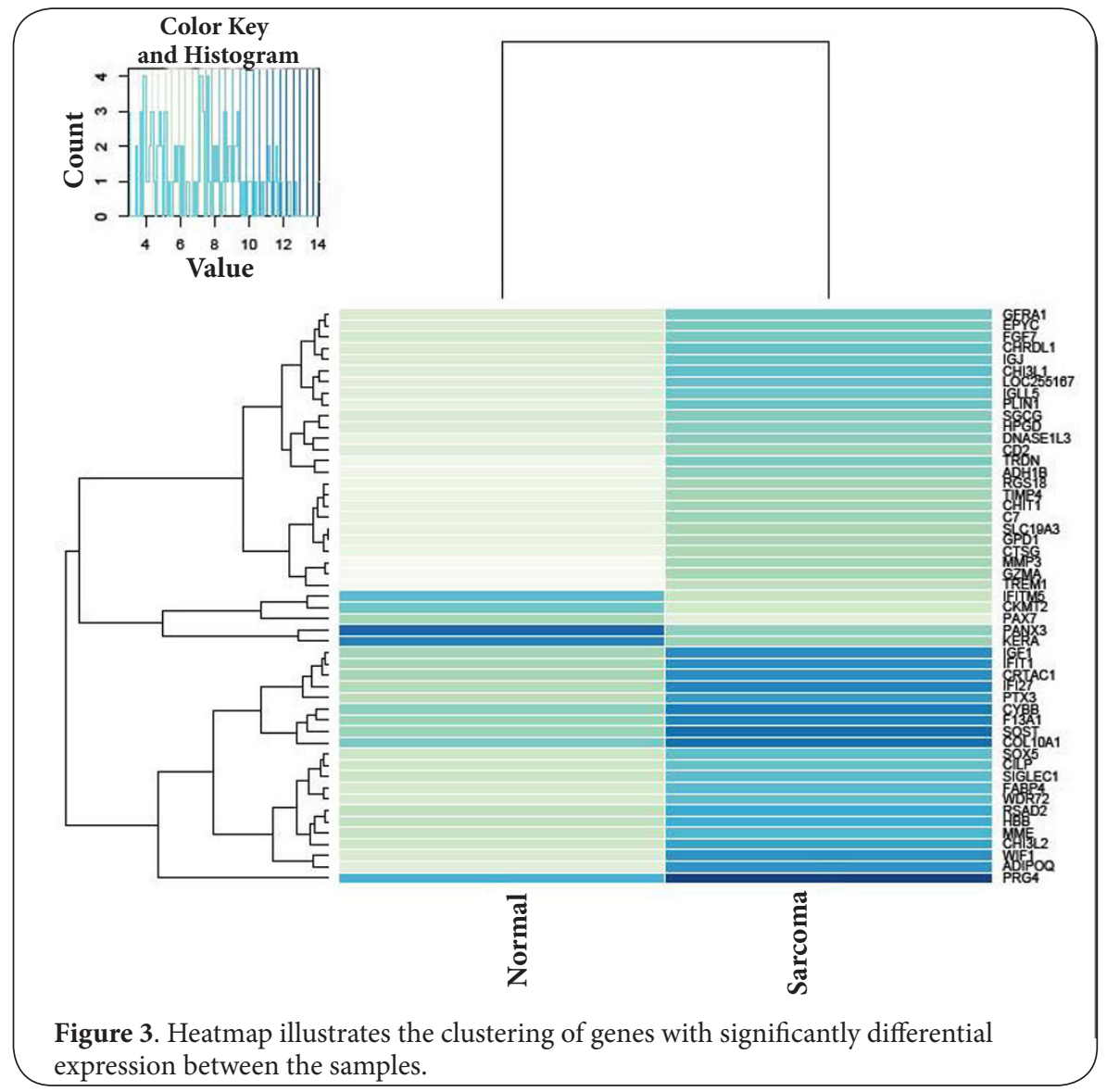

pathologies $[29,30]$. Serum adiponectin levels have shown to be inversely associated with bone mineral density [31]. Our immunohistological analysis confirmed high expression of adiponectin in osteoid. Therefore, adiponectin could be useful marker for OS patients as well.

WIF1 is a gene with very clear involvement in oncogenesis. Generally, WIF1 is silenced by epigenetic inactivation during cancer development, but this is not limited to osteosarcoma $[19,20]$. WIF1 is inhibitor of Wnt signalling and therefore it is involved in development and remodelling of different tissues [32]. What is somewhat controversial is our finding of increased expression of WIF1 in OS patients because it supposed to be silenced or down-regulated in cancer samples [20]. In our study we clearly detected up-regulation of WIF1 in sarcoma patient and this may indicate suppression of Wnt signalling in our sample. This hypothesis needs to get more confirmation with additional studies. On the other hand, increased sclerostin (SOST) expression supports the idea that Wnt signalling is suppressed in the patients in our study. Namely, increased SOST is related to the inhibition of Wnt signalling [33]. Therefore, increased SOST level fits very well with increased WIF1 what decreases activity of Wnt signalling.

SOST seems to be antagonist for Wnt signalling and therefore, up-regulation of WIF1 and SOST seems to fit with each other [33-35]. This means that our finding generates functional network describing the restructuring activity in the bone during tumorigenesis. Down-regulation of Wnt signalling pathway in osteosarcoma is also described in some earlier studies. Earlier studies have similarly found clear downregulation of Wnt signalling in 25 high-grade prechemotherapy biopsies [36]. In many studies the comparisons are not made between healthy bone and osteosarcoma, therefore not all published gene expression-profiling studies are comparable with ours $[37,38]$. Therefore, some controversies exist about the involvement of Wnt signalling pathway in OS development.

Interestingly, in OS sample we found quite many genes related to the adipocyte functioning. Perilipin 1 or PLIN1 is one example. This gene produces protein what coats the lipid storage droplets in adipocytes and protects them until they can be broken down by lipase $[39,40]$. Similarly, FABP4 is fatty acid binding protein 4 and is described to be specific for adipocytes [41]. Two explanations are possible. This finding can reflect that during tumorigenesis osteoblasts differentiate to adipocytes. On the other hand, this can be also normal phenotype of osteosarcoma cells. According to literature, both variants have been described. Ultrastructural analysis of osteosarcoma cell described lipid droplets in all types of osteosarcoma cells [42]. Osteoblasts can trans-differentiate to 


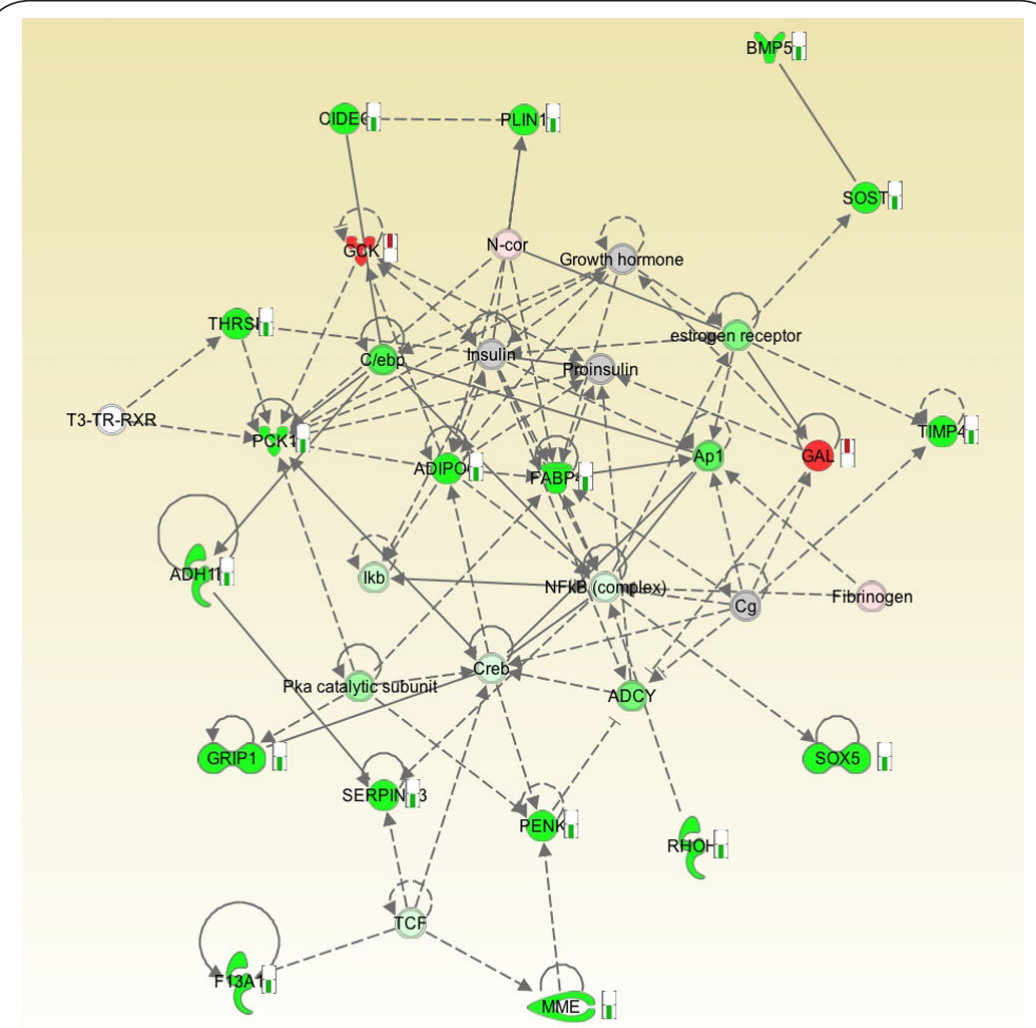

Figure 4. Ingenuity Pathway Analysis software was used for functional analysis to define genetic networks related to the osteosarcoma development. Functional analysis identified "Hematological Disease, Metabolic Disease, Endocrine System Development and Function" network to be activated in sarcoma sample. Genes with green colour are down regulated and genes in red colour are up regulated. This graph illustrates functional interactions between differentially expressed genes in sarcoma sample.

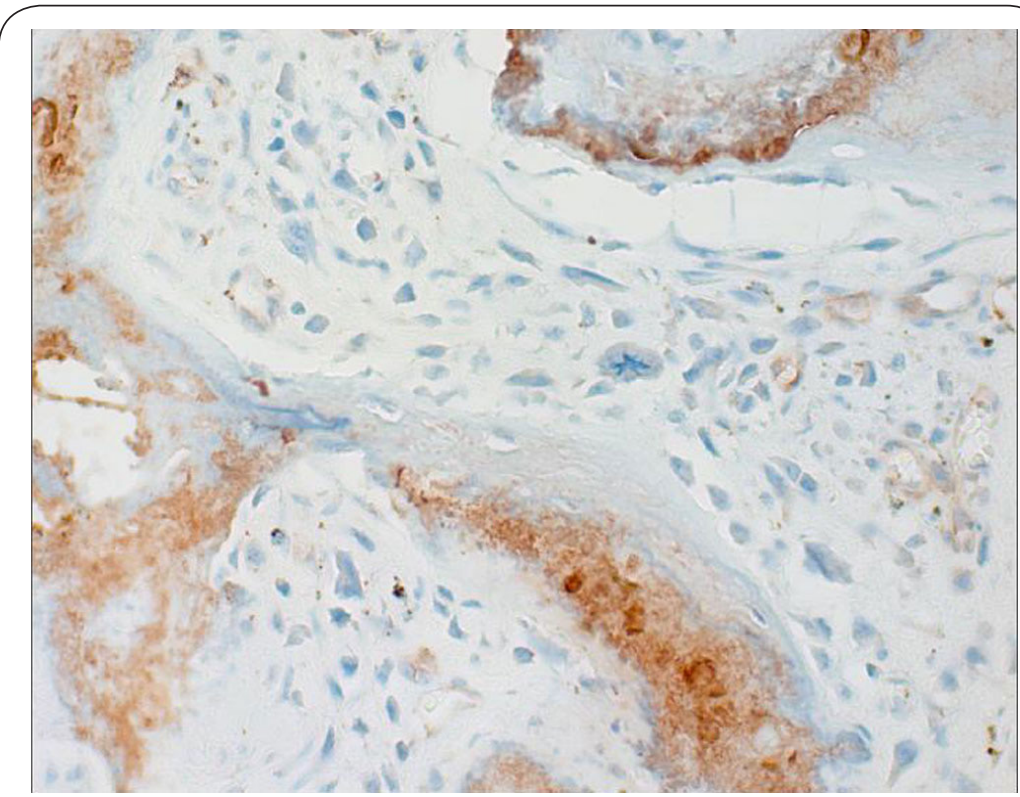

Figure 5. Photomicrograph of adiponectin immunohistochemical staining illustrates positive staining in sarcoma sample. ( $400 \mathrm{x}$ magnification) 
Märtson et al. Genomics Discovery 2013,

http://www.hoajonline.com/journals/pdf/2052-7993-1-3.pdf

doi: $10.7243 / 2052-7993-1-3$

adipocytes by inhibition of gap-junctional communication or by hormonal stimulation $[\mathbf{4 3}, \mathbf{4 4}]$. Taken together, adipocyte specific transcripts in osteosarcoma sample are quite common and this finding is in accordance of the literature.

Our study has some very clear limitations. For instance, sample size was very small in our study. Analysis based on single sample is very exploratory and does not provide conclusive evidence. We are fully aware, that the results presented here, should be verified in independent, large sample.

\section{Conclusions}

In conclusion, our whole transcriptome profiling of osteosarcoma identified down regulation of Wnt signalling pathway and adiponectin as potential biomarker for osteosarcoma relevant for the tumour progression. These changes can potentially explain molecular nature of the osteosarcoma.

\section{Competing interests}

The authors declare that they have no competing interests.

\section{Authors' contributions}

\begin{tabular}{|l|c|c|c|c|c|c|}
\hline Authors' contributions & AM & SK & ER & EP & TE & KM \\
\hline Research concept and design & $\checkmark$ & $\checkmark$ & $\checkmark$ & $\checkmark$ & -- & $\checkmark$ \\
\hline Collection and/or assembly of data & $\checkmark$ & $\checkmark$ & $\checkmark$ & $\checkmark$ & $\checkmark$ & $\checkmark$ \\
\hline Data analysis and interpretation & -- & $\checkmark$ & -- & -- & -- & $\checkmark$ \\
\hline Writing the article & -- & $\checkmark$ & -- & -- & -- & -- \\
\hline Critical revision of the article & $\checkmark$ & -- & -- & -- & -- & $\checkmark$ \\
\hline Final approval of article & $\checkmark$ & $\checkmark$ & $\checkmark$ & $\checkmark$ & $\checkmark$ & $\checkmark$ \\
\hline Statistical analysis & -- & $\checkmark$ & -- & -- & -- & -- \\
\hline
\end{tabular}

\section{Acknowledgement}

The European Regional Development Fund together with the Archimedes Foundation supported this study.

\section{Publication history}

EIC: Viroj Wiwanitkit, Hainan Medical University, China.

Recevied: 11-Oct-2013 Revised: 20-Nov-2013

Accepted: 02-Dec-2013 Published: 10-Dec-2013

\section{References}

1. Picci P. Osteosarcoma (osteogenic sarcoma). Orphanet J Rare Dis. 2007; 2:6. | Article | PubMed Abstract | PubMed Full Text

2. Helman LJ and Meltzer P. Mechanisms of sarcoma development. Nat Rev Cancer. 2003; 3:685-94. | Article | PubMed

3. Wadayama B, Toguchida J, Yamaguchi T, Sasaki MS and Yamamuro T. p53 expression and its relationship to DNA alterations in bone and soft tissue sarcomas. Br J Cancer. 1993; 68:1134-9. | Article | PubMed Abstract | PubMed Full Text

4. Nakase M, Inui M, Okumura K, Kamei T, Nakamura S and Tagawa T. p53 gene therapy of human osteosarcoma using a transferrin-modified cationic liposome. Mol Cancer Ther. 2005; 4:625-31. | Article | PubMed

5. Baron R and Rawadi G. Targeting the Wnt/beta-catenin pathway to regulate bone formation in the adult skeleton. Endocrinology. 2007; 148:2635-43. | Article | PubMed

6. Gibault L, Perot G, Chibon F, Bonnin S, Lagarde P, Terrier P, Coindre JM and Aurias A. New insights in sarcoma oncogenesis: a comprehensive analysis of a large series of 160 soft tissue sarcomas with complex genomics. J Pathol. 2011; 223:64-71. | Article I PubMed

7. Vijayakumar S, Liu G, Rus IA, Yao S, Chen Y, Akiri G, Grumolato L and Aaronson SA. High-frequency canonical Wnt activation in multiple sarcoma subtypes drives proliferation through a TCF/beta-catenin target gene, CDC25A. Cancer Cell. 2011; 19:601-12. | Article | PubMed Abstract | PubMed Full Text

8. Flores RJ, Li Y, Yu A, Shen J, Rao PH, Lau SS, Vannucci M, Lau CC and Man TK. A systems biology approach reveals common metastatic pathways in osteosarcoma. BMC Syst Biol. 2012; 6:50. I Article I PubMed Abstract I PubMed Full Text

9. Cai Y, Mohseny AB, Karperien M, Hogendoorn PC, Zhou G and CletonJansen AM. Inactive Wnt/beta-catenin pathway in conventional highgrade osteosarcoma. J Pathol. 2010; 220:24-33. I Article I PubMed

10. Kuijjer ML, Hogendoorn PC and Cleton-Jansen AM. Genome-wide analyses on high-grade osteosarcoma: making sense of a genomically most unstable tumor. Int J Cancer. 2013; 133:2512-21. | Article | PubMed

11. Fletcher JA, Gebhardt MC and Kozakewich HP. Cytogenetic aberrations in osteosarcomas. Nonrandom deletions, rings, and double-minute chromosomes. Cancer Genet Cytogenet. 1994; 77:81-8. | Article | PubMed

12. Pakos EE, Nearchou AD, Grimer RJ, Koumoullis HD and Abudu A. Prognostic factors and outcomes for osteosarcoma: an international collaboration. Eur J Cancer. 2009; 45:2367-75. | Article | PubMed

13. Lewis IJ, Nooij MA, Whelan J, Sydes MR and Grimer R. Improvement in histologic response but not survival in osteosarcoma patients treated with intensified chemotherapy: a randomized phase III trial of the European Osteosarcoma Intergroup. J Nat/ Cancer Inst. 2007; 99:112-28. | Article | PubMed

14. Eselgrim M, Grunert $H$, Kuhne T, Zoubek A, Kevric M, Burger $H$, Jurgens $H$, Mayer-Steinacker R, Gosheger $G$ and Bielack SS. Dose intensity of chemotherapy for osteosarcoma and outcome in the Cooperative Osteosarcoma Study Group (COSS) trials. Pediatr Blood Cancer. 2006; 47:42-50. | Article | PubMed

15. Anninga JK, Gelderblom H, Fiocco M, Kroep JR, Taminiau AH, Hogendoorn PC and Egeler RM. Chemotherapeutic adjuvant treatment for osteosarcoma: where do we stand? Eur J Cancer. 2011; 47:2431-45. | Article | PubMed

16. Anders $S$ and Huber W. Differential expression analysis for sequence count data. Genome Biol. 2010; 11:R106. | Article | PubMed Abstract | PubMed Full Text

17. Benjamini Y, Hochberg Y. Controlling the False Discovery Rate: A Practical and Powerful Approach to Multiple Testing. Journal of the Royal Statistical Society Series B (Methodological). 1995;57: 289-300. | Article

18. Wu J, Fang J, Yang Z, Chen F, Liu J and Wang Y. Wnt inhibitory factor-1 regulates glioblastoma cell cycle and proliferation. J Clin Neurosci. 2012; 19:1428-32. | Article | PubMed

19. Yang SH, Li SL, Dong ZM and Kan QC. Epigenetic inactivation of Wnt inhibitory factor-1 in human esophageal squamous cell carcinoma. Oncol Res. 2012; 20:123-30. | Article | PubMed

20. Kansara M, Tsang M, Kodjabachian L, Sims NA, Trivett MK, Ehrich M, Dobrovic A, Slavin J, Choong PF, Simmons PJ, Dawid IB and Thomas DM. Wnt inhibitory factor 1 is epigenetically silenced in human osteosarcoma, and targeted disruption accelerates osteosarcomagenesis in mice. J Clin Invest. 2009; 119:837-51. | Article | PubMed Abstract | PubMed Full Text

21. Kawa S, Fujimoto J, Tezuka T, Nakazawa T and Yamamoto T. Involvement of BREK, a serine/threonine kinase enriched in brain, in NGF signalling. Genes Cells. 2004; 9:219-32. I Article I PubMed

22. Bao BY, Pao JB, Lin VC, Huang CN, Chang TY, Lan YH, Lu TL, Lee $\mathrm{HZ}$, Chen LM, Ting WC, Hsieh CJ and Huang SP. Individual and cumulative association of prostate cancer susceptibility variants with clinicopathologic characteristics of the disease. Clin Chim Acta. 2010; 411:1232-7. | Article | PubMed 
Märtson et al. Genomics Discovery 2013,

23. Harries LW, Perry JR, McCullagh $P$ and Crundwell M. Alterations in LMTK2, MSMB and HNF1B gene expression are associated with the development of prostate cancer. BMC Cancer. 2010; 10:315. | Article | PubMed Abstract | PubMed Full Text

24. Kim ST, Cheng Y, Hsu FC, Jin T, Kader AK, Zheng SL, Isaacs WB, Xu J and Sun J. Prostate cancer risk-associated variants reported from genomewide association studies: meta-analysis and their contribution to genetic Variation. Prostate. 2010; 70:1729-38. | Article | PubMed Abstract I PubMed Full Text

25. Marty I, Faure J, Fourest-Lieuvin A, Vassilopoulos S, Oddoux S and Brocard J. Triadin: what possible function 20 years later? J Physiol. 2009; 587:3117-21. | Article | PubMed Abstract | PubMed Full Text

26. Zhou W, Liu Y and Zhong DW. Adiponectin (ADIPOQ) rs2241766 G/T polymorphism is associated with risk of cancer: evidence from a metaanalysis. Tumour Biol. 2013; 34:493-504. I Article I PubMed

27. Chiu YC, Shieh DC, Tong KM, Chen CP, Huang KC, Chen PC, Fong YC, $\mathrm{Hsu} \mathrm{HC}$ and Tang $\mathrm{CH}$. Involvement of AdipoR receptor in adiponectininduced motility and alpha2beta1 integrin upregulation in human chondrosarcoma cells. Carcinogenesis. 2009; 30:1651-9. | Article | PubMed

28. Tang $\mathrm{CH}$ and Lu ME. Adiponectin increases motility of human prostate cancer cells via adipoR, p38, AMPK, and NF-kappaB pathways. Prostate. 2009; 69:1781-9. | Article | PubMed

29. Magni P, Dozio E, Galliera E, Ruscica M and Corsi MM. Molecular aspects of adipokine-bone interactions. Curr Mol Med. 2010; 10:522-32. | Article | PubMed

30. Ruscica M, Steffani $L$ and Magni P. Adiponectin interactions in bone and cartilage biology and disease. Vitam Horm. 2012; 90:321-39. | Article | PubMed

31. Register TC, Divers J, Bowden DW, Carr JJ, Lenchik L, Wagenknecht LE, Hightower RC, Xu J, Smith SC, Hruska KA, Langefeld CD and Freedman BI. Relationships between serum adiponectin and bone density, adiposity and calcified atherosclerotic plaque in the African American-Diabetes Heart Study. J Clin Endocrinol Metab. 2013; 98:1916-22. | Article | PubMed

32. Boudin E, Fijalkowski I, Piters E and Van Hul W. The role of extracellular modulators of canonical Wnt signaling in bone metabolism and diseases. Semin Arthritis Rheum. 2013; 43:220-40. | Article I PubMed

33. Gaudio A, Privitera F, Battaglia K, Torrisi V, Sidoti MH, Pulvirenti I, Canzonieri E, Tringali $G$ and Fiore CE. Sclerostin levels associated with inhibition of the Wnt/beta-catenin signaling and reduced bone turnover in type 2 diabetes mellitus. J Clin Endocrinol Metab. 2012; 97:3744-50. | Article | PubMed

34. Kim JH, Liu X, Wang J, Chen X, Zhang H, Kim SH, Cui J, Li R, Zhang W, Kong Y, Zhang J, Shui W, Lamplot J, Rogers MR, Zhao C, Wang N, Rajan P, Tomal J, Statz J, Wu N, Luu HH, Haydon RC and He TC. Wnt signaling in bone formation and its therapeutic potential for bone diseases. Ther Adv Musculoskelet Dis. 2013; 5:13-31. I Article | PubMed Abstract | PubMed Full Text

35. Yu L, van der Valk M, Cao J, Han CY, Juan T, Bass MB, Deshpande C, Damore MA, Stanton R and Babij P. Sclerostin expression is induced by BMPs in human Saos-2 osteosarcoma cells but not via direct effects on the sclerostin gene promoter or ECR5 element. Bone. 2011; 49:1131-40. | Article | PubMed

36. Cleton-Jansen AM, Anninga JK, Briaire-de Bruijn IH, Romeo S, Oosting J, Egeler RM, Gelderblom H, Taminiau AH and Hogendoorn PC. Profiling of high-grade central osteosarcoma and its putative progenitor cells identifies tumourigenic pathways. Br J Cancer. 2009; 101:1909-18. | Article | PubMed Abstract | PubMed Full Text

37. Kubista B, Klinglmueller F, Bilban M, Pfeiffer M, Lass R, Giurea A, Funovics PT, Toma C, Dominkus M, Kotz R, Thalhammer T, Trieb K, Zettl T and Singer CF. Microarray analysis identifies distinct gene expression profiles associated with histological subtype in human osteosarcoma. Int Orthop. 2011; 35:401-11. | Article | PubMed Abstract | PubMed Full $\underline{\text { Text }}$

38. Li JP, Liu LH, Li J, Chen Y, Jiang XW, Ouyang YR, Liu YQ, Zhong H, Li H and Xiao T. Microarray expression profile of long noncoding RNAs in human osteosarcoma. Biochem Biophys Res Commun. 2013; 433:200-6. | Article I PubMed

39. Clifford GM, Londos C, Kraemer FB, Vernon RG and Yeaman SJ. Translocation of hormone-sensitive lipase and perilipin upon lipolytic stimulation of rat adipocytes. J Biol Chem. 2000; 275:5011-5. | Article | PubMed

40. Clifford GM, McCormick DK, Vernon RG and Yeaman SJ. Translocation of perilipin and hormone-sensitive lipase in response to lipolytic hormones. Biochem Soc Trans. 1997; 25:S672. I Pdf I PubMed

41. Baxa CA, Sha RS, Buelt MK, Smith AJ, Matarese V, Chinander LL, Boundy $\mathrm{KL}$ and Bernlohr DA. Human adipocyte lipid-binding protein: purification of the protein and cloning of its complementary DNA. Biochemistry. 1989; 28:8683-90. | Article | PubMed

42. Garbe LR, Monges GM, Pellegrin EM and Payan HL. Ultrastructural study of osteosarcomas. Hum Pathol. 1981; 12:891-6. I Article I PubMed

43. Schiller PC, D'Ippolito G, Brambilla R, Roos BA and Howard GA. Inhibition of gap-junctional communication induces the trans-differentiation of osteoblasts to an adipocytic phenotype in vitro. J Biol Chem. 2001; 276:14133-8. | Article | PubMed

44. Nuttall ME, Patton AJ, Olivera DL, Nadeau DP and Gowen M. Human trabecular bone cells are able to express both osteoblastic and adipocytic phenotype: implications for osteopenic disorders. J Bone Miner Res. 1998; 13:371-82. | Article I PubMed

\section{Citation:}

Märtson A, Kõks S, Reimann E, Prans E, Erm T and Maasalu K. Transcriptome analysis of osteosarcoma identifies suppression of wnt pathway and upregulation of adiponectin as potential biomarker. Genomics Discov. 2013; 1:3. http://dx.doi.org/10.7243/2052-7993-1-3 